\title{
A Problemática da Tradução dos Upanixades
}

\author{
Octavio da Cunha Botelho
}

\begin{abstract}
Resumo: Este estudo pretende apontar os problemas na tradução dos textos upanixádicos, quer no meio religioso ou acadêmico. Ademais, apresentar algumas soluções para estas dificuldades alcançadas até agora, devido, principalmente, às contribuições acadêmicas e filológicas.

Palavras-chave: Hinduismo, Tradução Sânscrita, Upanixades, Problemática.
\end{abstract}

\section{Dificuldades na Tradução da Poesia SÂnscrita}

Qualquer tradutor de poesias reconhece a dificuldade existente ao traduzir obras poéticas para outras línguas. Pois, é difícil transmitir a mesma emoção do poema original através de uma tradução. Dificilmente um leitor brasileiro sentirá o mesmo sabor, que um leitor britânico, ao ler The Lady of Shalott de Alfred Tennyson, através de uma tradução portuguesa. Da mesma maneira, não será possível imprimir o mesmo paladar, que sentiria o leitor brasileiro, em um leitor britânico que se dispusesse a ler as obras de Guimarães Rosa em inglês. Trata-se de diferenças lingüísticas e culturais. Por exemplo, nas obras de Kalidasa, um dos mais admirados poetas e dramaturgos da literatura sânscrita, são encontradas passagens em que são utilizadas palavras com mais fonemas nasais, quando os casais se beijam, pois estão com as bocas ocupadas. Este é um genial recurso artístico-fonético da língua sânscrita impossível de ser reproduzido ou reconhecido em traduções. As línguas têm seus recursos e suas limitações na relação de uma com as outras. Portanto, sempre, na avaliação da qualidade das traduções, tem se levar em conta os recursos e as limitações da língua original em comparação aos da língua receptora. Ade- 
mais, as habilidades e as limitações do tradutor são fatores influentes e não podem ser desconsidaradas. ${ }^{1}$

Quanto à poesia sânscrita, Arthur B. Keith, um importante estudioso e tradutor do século XX, observa: "Os grandes poetas da Índia escreveram para públicos eruditos. Eles eram mestres do saber da sua época, com muito treinamento no uso da língua. Eles buscavam comover pela sutileza e não pela simplicidade. Eles tinham a sua disposição uma língua simplesmente bela, que exigia os mais efetivos e elaborados metros. Sob tais circunstâncias, era inevitável que suas obras teriam de ser difíceis... É nos grandes escritores da Kavya (poesia), encabeçados por Kalidasa, que nós encontramos profundidade de sentimento pela vida e pela natureza, combinada com perfeição de expressão e de ritmo. A literatura Kavya (poética) inclui algumas das grandes poesias do mundo, mas nunca pode se esperar que atinja ampla popularidade no Ocidente, pois é essencialmente intraduzível. Os esforços dos tradutores ingleses com traduções em verso ficam inevitavelmente abaixo de uma mediocridade tolerável, sua tepidez difusa que contrasta dolorosamente com a brilhante condensação de estilo, a elegância do metro e a íntima adaptação do som ao sentido do original". ${ }^{2}$

As razões são que "os versos sânscritos são simétricos. Eles têm uma forma métrica muito estrita e definida, e freqüentemente padrões sonoros extremamente complexos e sutis de assonância e aliteração. As qualidades de ritmo, de simetria, da música das palavras, não podem ser diretamente transpostas para outra língua e, para isso, não há nenhuma solução perfeita. A solução mais aproximada que nossas limitações permitem, e estas limitações, deve-se lembrar, não são só as limitações de nossas próprias habilidades impostas pela natureza, mas também incluem aquelas impostas pela natureza da língua receptora. A tentativa, em geral, involve o que parece para o tradutor ser um completo desmembramento do verso original em componentes de sentido, e a subseqüente criação de um novo poema, onde estes componentes são reconstruídos e confinados, freqüentemente, com muito esforço, num novo padrão formal de palavras. O máximo que se pode esperar é que, nos mais bem sucedidos exemplos, o novo poema, enquanto reten-

1. A diferença entre o valor do original e o da tradução deve ser observada, mas não a ponto de dar crédito ao depreciativo provérbio indiano de que "ler uma obra através de uma tradução é o mesmo que engolir um alimento já mastigado por outra pessoa". Ou seja, o sabor do alimento já foi retirado. Esta é uma visão extremista, uma vez que as traduções não devem ser repugnadas a tal ponto. Muito do sabor e do clima da obra original pode ser reproduzido numa tradução.

2. Citado por John Brough em Poems from the Sanskrit, p. 20-1. 
do o máximo possível do sentido do conteúdo do original, também transmitirá ao leitor alguma atmosfera similar àquela do poema original. Naturalmente, isto não é sempre alcançado". ${ }^{3}$

E quando passamos da literatura poética (Kavya) para a literatura religiosa (Shruti), imagine o tanto que estas dificuldades poderão ser aumentadas, quando se tratar de traduções de obras de mais de dois mil anos, de caráter didático, com termos técnicos com significados divergentes, numa redação condensada, compostas numa língua diferente gramaticalmente das línguas modernas e, sobretudo, produzidas em época e ambiente culturais tão distintos. E ainda mais, a dificuldade é aumentada quando estas obras sânscritas estão compostas numa linguagem implícita, enigmática e insinuante, tal como é o caso dos Upanixades. $^{4}$

\section{A Posição dos Upanixades na Literatura Védica}

Literalmente a palavra Upa-ni-shad significa: ni-shad = sentar-se e upa = junto. Em virtude das circunstâncias em que este "sentar-se junto" acontecia no passado, extraiu-se o seguinte significado para a palavra: "sentar-se junto ao mestre para ouvir a instrução". Portanto, expressa uma idéia de reunião, palestra ou sessão. Esta idéia de sessão, combinada com a tradição hindu de atribuir à palavra Upanishad o significado de Rahasya (segredo), levou os estudiosos contemporâneos a interpretar a palavra Upanishad como "instrução secreta", "doutrina secreta" ou "significado secreto".

A literatura religiosa do Hinduismo, de um modo geral, está dividida em duas categorias principais de textos: o Shruti (literalmente: "aquilo que tem sido ouvido"), e o Smriti (literalmente: "aquilo que tem sido relembrado"). De uma forma mais generalizada, porém não mais precisa, Shruti e Smriti têm sido traduzidos como "Revelação" e "Tradição" respectivamente. Do ponto de vista da ortodoxia hindu, aos Shrutis são atribuídos autoria divina (Rshis), e aos Smritis, autoria humana. Por isso, os Shrutis ocupam o topo da hierarquia canônica, seguidos pelos Smirtis. É o corpus de escrituras mais autorizado e o único seguido por todas as

3. Idem, p. 23.

4. Upanixade é transliteração portuguesa para a palavra sâncrita Upanishad. Portanto, para a transliteração das palavras sâncritas que já tiverem correspondentes no volabulário da língua portuguesa, será utilizada aqui a ortografia do Dicionário Houaiss da Língua Portuguesa. As palavras que ainda não tiverem, será mantida a transliteração da língua inglesa, por ser a internacionalmente utilizada. 
correntes do Hinduismo. Nesta categoria de escrituras, os Shrutis, está um conjundo de escrituras (corpus) conhecido coletivamente como o $V E D A$, que significa literalmente, conhecimento, ou seja, o conhecimento por excelência. Os Vedas, como são também conhecidos, representam os mais antigos registros da religião hindu e estão divididos, num primeiro momento, nas seguintes coleções (Samhitas) de hinos:

1) RIG VEDA SAMHITA - coleção de hinos do Rig Veda, isto é, o Veda ou conhecimento dos hinos de louvor (Rik).

2) SAMA VEDA SAMHITA - coleção de hinos do Sama Veda, o conhecimento dos hinos melodiosos (Saman).

3) YAJUR VEDA SAMHITA - coleção de hinos do Yajur Veda, o conhecimento dos rituais e dos sacrifícios (Yajur).

4) ATHARVA VEDA SAMHITA - coleção de hinos do Atharva Veda, conhecimento dos encantamentos e das palavras mágicas (Atharvan).

O Rig Veda Samhita é o mais antigo de todos e fornece muito dos seus hinos para as outras Samhitas (coleções de hinos), ou seja, muitos hinos do Rig são repetidos nos demais Vedas, sobretudo, no Sama Veda.

Surgida a necessidade de interpretar e de organizar os sacrifícios e os rituais, juntamente com os hinos que os acompanhavam, criaram-se manuais em prosa para os rituais e sacrifícios denominados Brahmanas (manuais dos sacerdotes), que foram anexados às Samhitas (coleções de hinos). Com a diversificação das interpretações, novas idéias sobre regras de vida e de meditação tiveram de ser registradas em textos denominados Aranyakas (manuais do residente na floresta) que, por sua vez, foram anexados aos Brahmanas. E, finalmente, quando especulações filosóficas surgiram, foram registradas em textos conhecidos como Upanixades (textos especulativos) que, também, foram anexados aos Aranyakas. De maneira que, no passado, à cada Samhita (coleção de hinos) dos quatro Vedas, foram anexados o Brahmana, o Aranyaka e o Upanixade, à medida que os ritos, os sacrifícios, as disciplinas e as doutrinas especulativas cresciam em complexidade e diversidade.

Portanto, cada uma destas porções dos Vedas pode ser definida assim em sua ordem cronológica de composição:

1) SAMHITAS - coleções de hinos, orações, invocações, canções mágicas, encantamentos e palavras de poder (Mantrans) empregados nos sacrifícios e rituais. 
2) BRAHMANAS - extensos textos em prosa que contém explanações teológicas relativas às diretrizes em que o sacerdote deve conduzir os sacrifícios e rituais.

3) ARANYAKAS - textos relativos às regras de vida e de meditação, juntamente com os ritos a serem praticados pelo Vanaprastha (residente na floresta).

4) UPANIXADES - textos relativos às especulações filosóficas sobre a origem e a natureza do universo, do homem e do Ser Supremo (Brahman), bem como explanações sobre meditação e a Liberação (Moksha).

Destarte, os Upanixades são as derradeiras composições dos Shrutis, ou seja, a culminação do Veda. Por isso, são reconhecidos pela tradição hindu como o Vedanta (fim dos Vedas), por tratarem do tema culminante da literatura védica, a Liberação (Moksha), alcançada por meio do conhecimento do Ser Supremo (Brahman): o tema central dos Upanixades.

Existem referências da existência de mais de mil Upanixades no passado, porém, muitos se perderam. Atualmente, só é possível encontrar um pouco mais de duzentos. Destes, apenas de dez à quatorze são reconhecidos, conforme o critério de classificação, como Upanixades Maiores (Principais), os demais são considerados Upanixades Menores (Secundários). Os Upanixades Maiores são: Isha, Kena, Katha, Prashna, Mundaka, Mandukya, Taittiriya, Aitareiya, Chandogya, Brihadaranyaka, Swetaswatara, Maitrayaniya, Kaushitaki e Mahanarayaniya Upanishads.

\section{Traduções dos UpaniXades}

Estritamente falando, o que freqüentemente se chama de "tradução" dos Upanixades, ou dos textos Védicos, não é, na realidade, uma tradução propriamente dita, à maneira das traduções do inglês, do francês ou do espanhol para o português. É mais exato dizer que se trata de uma "tradução interpretativa", pois, uma tradução literal dos Upanixades para qualquer língua moderna torna-se incompreensível para o leitor. São necessários acréscimos e adaptações, em muitos casos, para que o sentido se faça inteligível. Ao empreender uma tarefa desta natureza, o tradutor terá de se preocupar com duas dimensões da fidelidade: a fidelidade literária (lingüística) e a fidelidade conceitual (cultural). A tradução (interpretação) ideal será aquela que melhor reproduzir estes dois aspectos simultaneamente. Porém, quanto aos Upanixades e outras obras sânscritas, é difícil, as vezes, conciliar na tradução o mesmo grau de fidelidade, destas duas dimensões, numa mesma passa- 
gem, em virtude das diferenças lingüísticas e conceituais. Uma vez ou outra, terá de se sacrificar uma em favor da outra. Em outras palavras, em certas passagens, será necessário sacrificar a fidelidade literária ou lingüística, quiçá em relação a poesia ou a riqueza simbólica, para melhor reproduzir o significado. Pois, em certas ocasiões, não é possível reproduzir em outra língua o significado exigido pelo contexto através da poesia peculiar a língua original. Em outras circunstâncias, será necessário sacrificar um pouco a precisão do significado para não se perder a extraordinária beleza de uma passagem poética. Enfim, é na tensão entre estas duas dimensões da fidelidade nas traduções que se encontra, em grande parte, a possibilidade de divergentes traduções, ou seja, um tradutor poderá se preocupar mais ou talvez menos com a fidelidade literária (artística), e outro poderá se preocupar mais ou talvez menos com a fidelidade conceitual.

Mas não é só isto que interfere nos contrastes das traduções, o engajamento religioso é outro fator influente. A preferência por esta ou aquela doutrina, faz o tradutor religioso ser conduzido para o sentido que ele pretende transmitir ao leitor. Evidentemente, com isso, o texto perde muito do seu sentido original. Também, a ausência, em muitas passagens dos Upanixades, de uma linguagem explicita e precisa, estimula o exercício da imaginação dos tradutores e intérpretes e, com isso, as conjecturas se multiplicam. Fato também comum em outras obras simbólicas e poéticas da Antigüidade. Por isso, não se deve esperar que as traduções atuais das obras antigas sejam muito mais que aproximações da linguagem e do pensamento dos antigos. Pois, quanto mais um tradutor se esforça para realizar uma tradução fiel de obras antigas, ele, na verdade, está, no máximo, tentando se aproximar mais ao sentido e à linguagem originais.

Importa ter claro na mente a diferença entre "tradução interpretativa" mencionada acima e "interpretação doutrinária". A primeira diz respeito a um pequeno aumento na articulação da linguagem e do significado, para troná-los claros e compreensíveis nas línguas modernas. A interpretação doutrinária (filosófica ou religiosa), por sua vez, corresponde a um passo mais adiante no processo de articulação dos significados. No entanto, não são raros os exemplos em que estas duas etapas da articulação se confundem, ou seja, o tradutor se aproveita da tradução interpretativa para imprimir, simultaneamente, sua interpretação doutrinária. Esta é a tradução geralmente conhecida como "tradução tendenciosa", e está impregnada na quase totalidade das traduções religiosas dos textos sagrados indianos.

Para se ter uma noção do quanto as traduções se divergem, em virtude dos fatores apontados acima, serão reproduzidas abaixo algumas traduções de diferen- 
tes tradutores, do primeiro verso do Isha Upanishad, para que seja possível a percepção do grau de divergência, bem como, também, o de aproximação, entre traduções de um mesmo verso em sânscrito.

"Tudo isto, tudo que move sobre a terra, deve ser ocultado no Senhor (Eu). Quando você tiver renunciado a tudo isto, você então poderá desfrutar. Não cobice a riqueza de nenhum homem". (F. Max Müller)

"Este universo inteiro é compenetrado pelo Senhor Hari. Ele (o universo) também depende da natureza primordial que, por sua vez, é também compenetrada por Ele (Hari). Somente Ele (Hari) é assim independente. Por esta razão, desfrute de tudo que lhe seja dado por Ele, e não busque riqueza de qualquer outra fonte". (Shrisha Rao)

"Absorva este universo em Deus e em tudo que vive na terra. Aquele que renuncia, desfruta realmente. Não deseje os bens dos outros". (Paul Deussen)

"Tudo isto, qualquer coisa que exista neste universo, deve estar encoberto pelo Senhor. Proteja o Eu pela renúncia. Não deseje o bem de nenhum homem”. (Swami Nikhilananda)

"Tudo isto é para a habitação do Senhor, tudo que for universo individual de movimento no movimento universal. Com esta renúncia, você deve desfrutar, não deseje a posse de nenhum homem". (Sri Aurobindo)

"Tudo que é mutável neste mundo efêmero, tudo isto deve ser envolvido pelo Senhor. Com esta renúncia (do mundo), sustente-se. Não cobice a riqueza de ninguém”. (Swami Sarvananda - A)

"Tudo que é mutável neste mundo efêmero, tudo isto deve ser visto como compenetrado pelo Senhor. Portanto, desfrute do mundo após renunciar ao desejo por estas coisas efêmeras. Não cobice pelas posses". (Swami Sarvananda - B) ${ }^{5}$

5. Traduções "A" e "B" de Swami Sarvananda referem-se as duas perspectivas mediante as quais este autor traduziu o Isha Upanishad na Upanishad Series publicado pela Sri Ramakrishna Math. Versão "A" se refere a tradução do ponto de vista monista, enquanto versão "B" se refere ao ponto de vista teísta. 
Contemple o universo na glória de Deus, e tudo que vive e move sobre a terra. Abandonando o transitório, encontre alegria no Eterno, não coloque seu coração nas posses do outro". (Juan Mascaró)

"Tudo isto deve ser envolvido pelo Senhor (Isha). Toda coisa movente no mundo móvel. Com esta renúncia, você deve desfrutar. Não cobice a riqueza de ninguém de jeito nenhum". (R. E. Hume)

"Todo este mundo, e aquilo que é o menor de tudo neste mundo, que o sustenta e o suporta, isto é, o Atman; são Brahman em associação com sua Shakti (manifestada) ou Brahma Shakti em si. Ignorando esta verdade, não se ocupe em ações por prazeres mundanos; busque sinceramente as beatitudes brahmicas, rejeite a riqueza obtida pelo suor". (Sri Janardana)

“Tudo isto é compenetrado pelo Senhor, tudo que é móvel e imóvel neste mundo. Com tal renúncia, desfrute (ou proteja). Não cobice a riqueza de ninguém”. (Swami Krishnananda)

"O Senhor está situado nos corações de todos. O Senhor é a suprema realidade. Sinta alegria nele através da renúncia. Não cobice nada. Tudo pertence ao Senhor”. (Eknath Easwaran)

"Tudo isto é habitado por Deus, tudo que move aqui neste universo móvel. Portanto, somente pela renúncia desfrute de todas as coisas. Não cobice o que pertença aos outros". (V. Jayaram)

"Envolvido pelo Senhor deve estar tudo isto, cada coisa que move na terra. Com esta renúncia, desfrute-se. Não cobice a riqueza de ninguém". (Ralph T. H. Griffith)

Salvo poucas exceções, o único trecho do verso em que as traduções se assemelham é o relativo ao último pé (Pada) do verso, os demais trechos são mais divergentes e, em alguns casos, estão traduzidos numa redação relativamente confusa, o que confirma o embaraço do tradutor. Bem, é justo esclarecer que este é um verso sânscrito com um significado original obscuro, de difícil tradução, propositadamente escolhido como exemplo. Entretanto, não é verdade que todos os versos e frases dos Upanixades apresentem o mesmo grau de dificuldade na tradução e, conseqüentemente, tantas possibilidades de traduções discordantes.

\section{Octavio da Cunha Botelho - A Problemática da Tradução dos Upanixades}


Estas dificuldades surgem pelas seguintes razões: as dificuldades lingüísticas (gramática, vocabulário, eufonia) e as dificuldades temáticas. Um tradutor poderá ser hábil na gramática sânscrita, porém desconhecer o assunto relativo ao texto que está traduzindo. Por outro lado, um tradutor poderá ser familiarizado com o tema da tradução, no entanto, inábil com a gramática. Na tensão da polaridade destes dois enfoques encontram-se discussões entre aqueles que defendem a primado do seu ponto de vista sobre o do outro. É comum um tradutor ou intérprete, mais apegado a prioridade do tema, criticar outros tradutores, mais inclinados à prioridade da língua e da gramática, por encobrirem ou deformarem o significado de certas passagens, bem como, deturparem o significado de termos técnicos, em virtude do excessivo zelo pela gramática. Já um tradutor mais apegado à gramática não se cansa de apontar as violências, os atropelos e os pisoteios na gramática sânscrita, cometidos por outros tradutores, mais deslumbrados pelo tema, no afã de chegarem ao significado e à interpretação pretendidos. Algumas críticas a outros tradutores chegam a ser tão acaloradas que, o próprio crítico se envolve em flagrante contradição. Veja o exemplo de Sri Aurobindo que critica veementemente o prof. Max Müller por ter traduzido inadequadamente as palavras sânscritas Purusha, Rayi e Tapas como Ser, Matéria e Ascese respectivamente. No entanto, ele (Aurobindo) utiliza estes mesmos significados para estas três palavras sânscritas na sua tradução inglesa do Prashna Upanishad. ${ }^{6}$

Com efeito, uma das grandes dificuldades para se encontrar o significado mais próximo de uma palavra ou expressão no vocabulário de outra língua, está, sem dúvida, na tradução de termos técnicos. Muitos tradutores estão de acordo que uma das palavras, muito freqüente nos Upanixades, mais difíceis de se achar, com precisão, termos equivalentes em línguas ocidentais, é a importante e significativa palavra Atman. Já foram tentados vários termos: Alma, Ser, Eu, Ego, Espírito, Princípio de Vida. O grande problema na tradução da palavra Atman, bem como de outros termos técnicos da língua sânscrita, está na variação do significado que recebem conforme o contexto. Representações metafóricas comparando o Atman à objetos ou à forças são, até hoje, motivo de discussão entre tradutores e intérpretes para saber seus significados. Muitas vezes, palavras ou expressões simbólicas irrompem no meio de contextos cosmogônicos, que resulta difícil, e em muitos casos torna-se conjetural, desvendar o significado metafísico ou filosófico por trás

6. Cf. The Upanishads, 1972, p. 58 e 296-8. 
do simbolismo. Veja o exemplo na primeira frase do Aitareya Upanishad: "No início, tudo isto era o Atman apenas, um só, não havia nada mais que piscava...". A palavra sânscrita para "piscava" é "Mishat". Ao traduzi-la, os tradutores se dividem entre a tradução literal ou a busca do significado subjacente à metáfora. No exemplo acima, alguns tradutores sugerem que a expressão "que piscava" significa "que vivia" (M. Müller), ou "que movia" (Aurobindo e E. Easwaran), ou "que levantava os olhos" (P. Deussen), ou até mesmo "que atuava como rival" (Sarvananda). E aqueles que preferem conservar a expressão literal "que piscava" (Nikhilananda e R. E. Hume).

Quando se percebe que o exemplo acima é apenas um dentre muitas outras palavras e expressões simbólicas, onde não se encontram traduções com significado consensual, pelos motivos apontados acima, o estudante crítico é levado a suspeitar do quanto a tradução dos Upanixades, em muitas passagens duvidosas, não poderá ser uma "tradução conjetural". Bem, antes de levar a sério esta suspeita, é preciso buscar as justificativas dos tradutores. As justificativas mais comuns são: a etimologia, com fundamento nas raízes das palavras; a citação de passagem de outra obra respeitada, onde a palavra ou a expressão aparece com o mesmo significado que pode ser mais claramente percebido; ou a interpretação no comentário de algum intérprete tradicional de grande autoridade. A primeira justificativa nem sempre é confirmada, uma vez que, como já assinalamos, o contexto muda o significado da palavra, portanto, a etimologia não é amiúde a regra. Também, fundamentar o significado pela interpretação de um intérprete autorizado, não representa significado consensual, visto que, um intérprete pode ser visto como autorizado por uma corrente doutrinária, mas não por outra. Max Müller, por exemplo, recorre aos comentários de Shankaracharya nas passagens duvidosas, no entanto, outras correntes filosóficas discordam dos significados interpretados por este comentarista vedantino. Mesmo quando se encontra um significado consensual, não pode se dizer, com certeza, que tenha se encontrado o significado original, pois, um significado consensual pode ser um significado convencional posteriormente cunhado. É o caso dos léxicos tardiamente elaborados que nos remetem apenas até os significados convencionais. Mas, significados filosóficos, místicos, psicológicos e éticos ultrapassam as convenções lingüísticas, e os Upanixades estão repletos destes significados sutis.

É raro encontrar um tradutor que reconheça que sua tradução tenha passagens que sejam traduções conjeturais. Os tradutores ortodoxos asseguram, alguns com veemente convicção, que suas traduções são a reprodução integral, mais fiel possível, do pensamento do compositor da obra traduzida. Estes nunca apontam que 
existam passagens obscuras de difícil tradução e que, a solução que eles estão utilizando para esclarecer as obscuridades seja a tradução conjetural.

Agora reflitam, se a compreensão do significado de muitas passagens upanixádicas sempre foi discordante entre os próprios hindus que as estudaram no Sânscrito original, então imagine como será esta compreensão quando estas obras são estudadas através de traduções em línguas modernas, que apresentam todos os embaraços, tal como analisamos acima, para reproduzir o significado preciso. Evidentemente, as divergências tendem a se multiplicarem.

Porém, nem tudo está perdido. Apesar das dificuldades apontadas acima, as traduções dos Upanixades já têm uma história e, de certa forma, pode se dizer que alcançaram um considerável aprimoramento. Após a tradução latina de Anquetil Duperron (Oupnekhat), Ram Mohan Roy fez traduções de quatro Upanixades (Mundaka, Kena, Katha e Isha) no início do século XIX. Estas últimas foram as primeiras traduções para uma língua ocidental moderna. Depois, seguiu-se uma série de publicações e traduções inglesas denominada Bibliotheca Indica, que publicou, dentre outras obras sânscritas, quase todos os Upanixades Maiores. Estas primeiras traduções são raras de ser encontradas atualmente, uma vez que não são mais reeditadas. As únicas traduções do século XIX que ainda são reeditadas, por se tornarem traduções clássicas, são as de Paul Deussen (Sechzig Upanishads des Veda, 1897) e a de F. Max Müller (The Upanishads, Sacred Books of the East, vols. 1 e 15, 1884-1900). Aliás, a deste último é a tradução mais imitada por outros "tradutores". Algumas "traduções" atuais não são nada mais do que reproduções da tradução deste professor de Oxford com pequenas alterações. Entretanto, esta novidade de traduzir obras sânscritas para línguas estrangeiras não foi, inicialmente, recebida com simpatia pelos ortodoxos hindus. Para eles, isto representava uma profanação: "as obras sagradas em sânscrito não podiam ser traduzidas para línguas impuras". Conta-se que Sir William Jones (1746-1794), um dos primeiros tradutores, enfrentou dificuldades, logo após sua chegada à Índia, para encontrar um professor de Sânscrito. Pois, naquela época, os hindus tinham receio de receberem punição social, por ensinar sua língua sagrada à um Mleccha (estrangeiro impuro), até que, finalmente, ele encontrou um hindu viúvo que não temia o boicote social e pôde, com isso, iniciar suas lições de Sânscrito. Houve, no início, indignação e relutância dos hindus ortodoxos, porém nada comparado à Inquisição do período renascentistas na Europa, ou aos violentos protestos dos fundamentalistas muçulmanos do século XX. Com o tempo a idéia foi aceita e, atualmente, temos um grande número de tradutores hindus. 
Obviamente, as traduções com intuito de divulgação e propaganda são as mais populares. Muitas são traduções simplificadas, para que possam ser lidas e entendidas por todos os leitores. Nelas, costuma-se sacrificar o refinamento da linguagem, bem como a complexidade e a obscuridade de certos temas, em favor da facilidade da leitura. Com isso, muitos leitores destas traduções, por não poderem ler no sânscrito original e, conseqüentemente, perceberem as distorções provocadas pela simplificação, são levados a pensar que dominam a compreensão dos Upanixades já na primeira leitura. O leitor interessado em conhecer esta modalidade de tradução basta consultar as traduções inglesas de Juan Mascaró e de Eknath Easwaran. Este último, por exemplo, traduziu termos técnicos, tão importantes para a ontologia dos Upanixades, tais como Brahman, Atman, Purusha e Akshara, em algumas passagens, como "Senhor de Amor" (Lord of Love). Não precisa ser nenhum crítico hábil para perceber a intenção do tradutor: adaptar a terminologia teológica dos Upanixades ao gosto cristão. Bem, esta pode ser uma eficiente estratégia proselitista, porém um lastimável empobrecimento da compreensão dos diferentes níveis de concepção do Ser Supremo da seminal ontologia upanixádica.

Muito populares são as traduções publicadas por instituições com interpretações inovadoras do Hinduismo, orientadas pela filosofia Vedanta. Por ser a filosofia religiosa dominante e mais popular da Índia atualmente, o número destas publicações é grande. Entre as mais conhecidas estão as publicações das traduções da Upanishads Series pela Sri Ramakrishna Math em Madras (atual Chennai), as traduções de Sri Aurobindo Ghose pelo Sri Aurobindo Ashram em Pondicherry, as traduções de Swami Nikhilananda pela Ramakrishna Mission, bem como as traduções e estudos de Swami Krishnananda, pela The Divine Life Society em Rishikesh.

Por outro lado, as traduções acadêmicas e críticas são mais raras, uma vez que não são atrativas aos religiosos na Índia ou no Ocidente, por isso não se tornam populares. São as vezes tão raras e desconhecidas do público em geral, que muitos pensam que nem sequer existem estas modalidades de estudos nos meios acadêmicos. A verdade é o contrário, estas atividades são intensas, a ponto de somar um grande número de traduções e de estudos publicados por universidades de várias partes do mundo. Os mais tradicionais centros de estudos do Sânscrito no Ocidente estão na Universidade de Oxford na Inglaterra e na Universidade de Harvard nos Estados Unidos da América, e na Índia, na Universidade de Calcutá. O volume de traduções é grande e a complexidade da tarefa é preocupante, que chegou a ser motivo de um simpósio exclusivamente sobre o assunto, no qual reuniram-se alguns dos principais estudiosos com experiência em tradução, em Maio de 1994, na

76 Octavio da Cunha Botelho - A Problemática da Tradução dos Upanixades

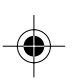


Universidade de Harvard. A coletânea das comunicações deste simpósio foi publicada pela Harvard Oriental Series - Opera Minora vol. 1, em 1996, com o título: Translanting, Translations, Translators from India to the West, editada pela Dra. Enrica Garzilli.

Diferente das traduções populares e religiosas, as acadêmicas não têm objetivos persuasivos e proselitistas, pois, tentam seguir a orientação científica e a imparcialidade crítica. O objetivo é, antes de tudo, a compreensão da língua, da literatura e da cultura dos indianos, e não a propaganda e a doutrinação religiosa. As traduções são mais criteriosas, imparciais e eruditas. Geralmente, os tradutores acadêmicos fazem pleno uso das outras traduções disponíveis, para consulta e comparação, bem como para a avaliação do estágio evolutivo do trabalho de traduções em geral. É neste ponto que, como foi mencionado acima, é possível se falar que o processo de tradução, após todos estes anos, alcançou um aprimoramento. Muitos pontos, quer lingüísticos ou temáticos, puderam ser corrigidos com o acúmulo de experiência na tradução. Desde os trabalhos pioneiros de Anquetil Duperron e Ram Mohan Roy, até as recentes traduções acadêmicas, interpõe-se um longo processo evolutivo.

Agora, o trabalho acadêmico e filológico mais desafiador, das últimas décadas, tem sido a criteriosa tentativa de isolar, cada vez mais, as traduções dos Upanixades das interpretações vedantinas. Pois, até recentemente, quase todas as traduções eram feitas com base nos comentários de Shankaracharya (séc. IX) e de outros intérpretes do período medieval (Ramanuja, Madhwa, etc.). No meio acadêmico, esta modalidade de tradução interpretativa foi influenciada sobremodo pelas traduções clássicas de Max Müller, Paul Deussen e Radhakrishnan. Segundo alguns estudiosos (E. Frauwallner, P. Olivelle e M. Witzel) esta é uma equivocada abordagem do ponto de vista do desenvolvimento do pensamento indiano. Nas palavras de Erich Frauwallner: "A fim de compreender corretamente a filosofia dos Upanixades, não é necessário, acima de tudo, introduzir coisas tardias neles. Especialmente, não é necessário interpretá-los mediante o idealismo monístico de Shankara, tal como Deussen tem feito. A doutrina de Shankara está separada dos mais antigos Upanixades por um período de mais de mil anos, e ela confia inteiramente em outras presuposições e opiniões que foram criadas apenas no período de transição. Ademais, não existe nenhuma filosofia uniforme e harmoniosa nos Upanixades. Só o sistema Vedanta tardio é que criou uma unidade artificial. Os antigos Upanixades apresentam apenas um número de textos isolados, que eram individualmente recitados como textos independentes. Eles foram transmitidos repetidamente em diferentes contextos e isto prova sua independência. A tarefa com a qual a ciência agora 
se depara é compreender estas diferentes doutrinas em sua originalidade, ordenálas e organizá-las, bem como explicar suas origens e seu desenvolvimento".7 O início desta revolução filológica nas traduções, foi marcado pela tradução crítica de Robert Ernest Hume, publicada pela Oxford University Press em 1931. Desde então, as traduções acadêmicas passaram a tratar os textos com mais precisão filológica, isto é, a princípio tratá-los como textos isolados e então em suas relações com outros Upanixades, bem como com os precedentes Brahmanas e Aranyakas. Diante disto, é possível perceber a dependência do trabalho de tradução em relação aos resultados dos estudos filológicos.

No entanto, para empreender esta tarefa, um amplo trabalho filológico foi necessário, pois não bastava compreender os Upanixades em sua perspectiva religiosa ou exegético-tradicional. Para tanto, foi necessário um abrangente e crítico estudo lingüístico, hermenêutico, histórico, cultural, antropológico, e até mesmo geográfico, para se encontrar jutificativas para esta desvinculação da intrepretação vedantina. No momento, este trabalho tem recebido um considerável avanço com os esforços do Dr. Michael Witzel, editor da Harvard Oriental Series, Opera Minora. Mesmo assim, ele não se encontra satisfeito com a situação atual das traduções upanixádicas, pois reconhece: "Os tão lidos e interpretados Upanixades, surpreeendentemente, em sua maioria, carecem ainda de uma edição crítica... Os Upanixades, contudo, devem ser tratados como textos encaixados em seu contexto védico. Isto não tem sido bem compreendido pelos Indólogos que tratam os Upanixades como peças separadas de literatura.... Alguns estudiosos védicos tem agora percebido a necessidade de afastá-los da influência Adwaita (Vedanta Monista), e tem ocasionalmente feito assim em suas traduções. O que nós finalmente esperamos é um detalhado e extenso tratamento de um Upanixade que explique claramente estes princípios e mostre sua aplicação". ${ }^{8}$ Em suma, uma criteriosa tradução dos Upanixades só pode ser feita, após um cuidadoso estudo filológico e científico do contexto cultural e histórico daquele período.

Por conseguinte, a avaliação do estado atual das traduções, em geral, nos revela uma intrincada teia de consenso e controvérsias. Diante deste quadro controvertido, o leitor poderá estar perguntando se é confiável, e até que ponto compensador, o estudo dos Upanixades. Bem, merece ser esclarecido, sobretudo, que este quadro controvertido é o resultado do aprimoramento do rigor no estudo e nas críticas das

7. History of Indian Philosophy, vol. I, p. 358-9.

8. Vedic Hinduism, p. 26.

78 Octavio da Cunha Botelho - A Problemática da Tradução dos Upanixades 
traduções. É esta rigorosidade, portanto, que nos assegura maior confiabilidade, do que antes, nos resultados dos trabalhos. Se não fosse a crítica das traduções, poderíamos ter hoje uma maior uniformidade nas traduções, o que é mais cômodo de se aceitar, tal como acontece nas traduções de seitas tradicionais, com base na confiança em uma ou outra autoridade religiosa, porém, com isso o que teríamos, seriam mais traduções doutrinárias do que traduções originais, ou seja, apenas nos possibilitaria conhecer o que os intérpretes hindus pensavam dos textos e não o sentido que os próprios compositores tinham em mente. Apesar de não existir tradução perfeita dos Upanixades, não é justo considerar desprezível o estudo destes antigos textos pelas traduções disponíveis. A verdade é que, a crítica das traduções, na atualidade, é mais rigorosa que no passado, em razão, principalmente, das contribuições dos círculos acadêmicos. Ademais, não convém terminar a análise deste assunto sem enfatizar que, em meio a todo este processo evolutivo das traduções, nem tudo é controvertido, há muito consenso.

\section{BIBLIOGRAFIA}

AUROBINDO, Sri. The Upanishads. Pondicherry: Sri Aurobindo Ashram, 1972, p. 53-60. BROUGH, John. Poems from the Sanskrit. London: Penguin Books, 1968, p. 19-35.

DEUSSEN, Paul. Sixty Upanisads of the Veda. Delhi: Motilal Banarsidass, 1990, passim. GARZILLI, Enrica (ed.). Translating, Translations, Translators from India to the West. Cambridge: Harvard Oriental Series - Opera Minora, vol. 1, 1996.

KLOSTERMAIER, Klaus K. Hinduism - A Short History. Oxford: Oneworld Publications, 2000, p.11-6 e 47-52.

MÜLLER, Max. The Upanishads - Sacred Books of the East, vol. I. Delhi: Motilal Banarsidass, 1993, Introduction, p. lvii e passim.

OLIVELLE, Patrick. The Early Upanisads - Annotated Text and Translation. Orford: Orford University Press, 1998, p. 04-16.

RADHAKRISHNAN, S. and Charles A. Moore. A Sourcebook in Indian Philosophy. Princeton: Princeton University Press, 1989, p. 37s.

WINTERNITZ, Maurice. A History of Indian Literature, Delhi: Motilal Banarsidass, 1990, vol. I, p. 47-51 e 209s; vol. III, p. 01s.

WITZEL, Michael and Stephanie Watkins Jamison. Vedic Hinduism, 1992, p. 14 e 26, passim, e-book: www.people.fas.harvard.edu/ witzel/vedica.pdf 
Abstract: This study aims at pointing out the problems in translating Upanishadic texts, either in religious or academic milieu. Also, some solutions to these difficulties reached so far, due mostly to the academical and filological contribuitions.

Keywords: Hinduism, Sanskrit Translations, Upanishads, Difficulties.

80 Octavio da Cunha Botelho - A Problemática da Tradução dos Upanixades 